\title{
The dilemma of biodiversity and specialization in agricultural development
}

\author{
Price Edwin, Kibriya Shahriar and Zhang Yu* \\ 578 John Kimbrough Blvd, AGSV Building, Room 240, College Station, TX, USA, 77843. \\ Accepted 12 March, 2013
}

\begin{abstract}
The impact and usefulness of specialization and diversification strategies of agricultural research in developing countries is reviewed. The specialization strategy is based on principles of optimization on resources allocation in the spatial context, and it typically prevails over diversification strategy that considers inter-temporal resources allocation. However, diversification strategies offer biodiversity, self-sufficiency, technical competency and risk neutralization. The benefits of the diversification strategy support farmers' independence and production increase, as well as long run conservation of biological resources. Research and development of new technologies for diversification can play an important role in the agricultural development of fragile developing nations.
\end{abstract}

Key words: Specialization, diversification, biodiversity, risk-taking.

\section{INTRODUCTION}

Neo-classical economics has evolved as a study of resource allocation, especially biological and natural resources. There are two ways to consider resource allocation: spatial and temporal allocation. Ricardo (1817) and Torrens (1815) established the principle that has come to be known as the law of comparative advantage. With subsequent neo-classical and modern refinement, the theory has stood for over 175 years. Contemporary economists (Jones, 1961; Shiozawa, 2007) have formulated and generalized the theory for the modern economic context. The law of comparative advantage suggests that welfare among nations is optimized when each specializes in the productive activities to which its resources are best suited. Specialization enables spatially dispersed economic units to ameliorate the problem of immobile natural resources. The theory is not only regarded as the basis for explaining international trade, but also popularly applied to guide production and trade among smaller economic units. With the development of globalization, economic geography is more and more influenced by international and interregional specialization (Davis and Weinstein, 1999). We call this "Specialization Strategy" in human productive activities.

The second way to extend the resources allocation study is to address the efficient distribution of resources over time, which is mainly studied by environmental and ecological economists. It states that a safe minimum standard (SMS) for biodiversity is needed to guarantee an economy's sustainability. A decrease in biodiversity threatens economic sustainability because some biological resources extinct now may become important resources in the future (Randall, 1991; Bishop, 1993). The preservation of biological diversity, as a consequence of the optimal inter-temporal utilization of natural resources, places the capability for bearing the 
risk of declining technologies with future generations, rather than through the production and savings activities of present generations. However, there is not as yet an established body of theory equivalent to the law of comparative advantage from which to derive the precepts of diversity. These two research approaches are parallel: both methods are designed to maximize the utility, or welfare of human beings, but depend on different dimensions. Nowadays, it is obvious that the former one dominates the latter in practice. Here we intend to argue whether specialization strategy is essentially better than the diversity approach in the developing countries.

\section{IMPACTS OF SPECIALIZATION STRATEGY}

The pervasive ramifications of economic behavior according to the theory of comparative advantage have characterized industrial and organizational development for the last century and a half. The persuasion has influenced not only industrialization at a national level, but each industry's approach to its own enterprise. Specialization in the utilization of labor on production lines, indeed the evolution of production lines, was the eventual expression at the level of the firm, of the macroeconomic precept of specialization. Emerging forms of enterprise according to comparative advantage are evident today. The admonition is often heard that "one cannot be all things to all people". Organizations are compelled by internal policies or by external evaluation, to focus on the few activities the organization does best, regardless of diverse attractive opportunities. Moreover, the emphasis upon "focus" in business and public institutions is an entrenched precept of organizational dogma (Deming, 1994). For instance, due to the improvement of transport facilities and the widespread use of chemical fertilizer, agricultural production is becoming regionally more specialized (Gregson, 1996; Lyons, 1988). Chisholm (1962) supported the use of agricultural specialization asserting that it is best suited for climatic and soil conditions in different areas, and thus obtains increased production. Among the varied applications of specialization strategy, at least three essential precepts have evolved as follows:

1. Reduction of the unit cost: Specialization can increase total production from a given set of resources. The Ford automobile manufacturing company assembly line established in Dearborn, Michigan, is the textbook example of specialization in production.

2. Instability: Specialized organizations, tools or tasks have a finite lifespan; a decline in their usefulness is expected such that income streams based upon specialized processes are inherently unstable (Day, 1981). Lines of unemployed persons whose specialized skills are no longer needed are as vivid an image of modern industry as the assembly line itself.
3. Internal risk-taking capacity: Since specialized processes will end, each should be operated to the fullest, and part of the gains saved for the time when the enterprise declines. Risk taking capacity is internal to the economic or organizational unit, or nation, and compensated from current income. "Making hay while the sun shines," aptly describes the situation today in many natural resource based industries, from agriculture to fishing, forestry, mining and petroleum.

To sum up, specialization strategy is an accepted economic theory and has popular derivations, especially in agriculture. The principle has an advantage to minimize the production cost, while specialization can also result in the instability of income streams, for which entrepreneurs prepare by exploiting technologies to their fullest, generating savings that can be used when current technologies fail.

\section{Traditional views on biodiversity}

The call to preserve biodiversity is on the ground that it must be preserved for future generations to enjoy and use (Tietenberg, 2009). The key point is that the present generation should not presume its own ability to accurately project technological needs in the future. Therefore, we should leave as many possible of the natural building blocks for future technologies in place, so that future generations can make their own adjustments to the evolving milieu. It is argued, in effect, that the capacity to bear the risk of a possible decline in the effectiveness of present technologies should be external to the current economy. Let future generations have access to the full range of biological resources that we have today, for the purpose of creating the means of their own livelihood.

Biodiversity is, on one hand, endangered by production activities of human beings (Gowdy and McDaniel, 1995). Theoretical analyses have been developed for the optimal inter-temporal utilization of fixed and renewable natural resources (Fisher et al., 1972). They studied the trade-off of natural resources between preservation and utilization, showing that it will be optimal to refrain from utilizing environments and leaving them in its natural state. When it comes to non-renewable resources, the increasing number of humans and the more intensively specialized human activities are pushing biological limits in terms of energy exhausting and species displacement or even species extinction. As for the renewable resources (for example, fishery), it has been argued that they may be exploited till the existence of "reproductive surplus", which is a balance between births, deaths, and somatic growth (Hilborn et al., 1995). However, the "invisible hand" of the market and technologies advances usually leads to the over-exploitation of resources (Regev et al., 1998). 
On the other hand, biodiversity is influenced by violent conflicts (McNeely, 2003). This point of view is often neglected because international conflicts are frequently conceived in narrow military terms. Violent conflict often leads to environmental degradation (such as deforestation, pollution of land and water), massive migrations of refugees, and reduction of natural conservation funds. For fragile conflict-prone developing nations, violence and conflicts can be major factors in the destruction of biodiversity (McNeely, 2003; Unruh et al., 2008). For stable developing countries with agrarian economies, promoting biological diversity in agriculture has become a common cause among pressure groups within and outside of agriculture.

It would be very difficult if not impossible to measure the value of biodiversity. In some extreme cases, researchers equal the value of biodiversity with the summed value of all the GNPs of all countries from now until the end of the world (Norton, 1988). When it comes to assessing the value of biodiversity the view of ecologists differs from the view of economists (Solow, 1993). Economic analysis would consider biodiversity as a commodity subjected to trade-offs and substitution at the margin, just as any other market commodities. Moreover, economists also recognize market failure and that market price may not reflect the true value of biodiversity. Gowdy (1997) proposes a more moderate point that the value of biodiversity must consist of market value, non-market value to humans, and the value of biodiversity to ecosystems. He admits that the market exchange value of environment service may justify importance of biodiversity, but it constitutes a small portion of total biodiversity value. To estimate the nonmarket value of biodiversity, several methods have been developed, such as contingent valuation, travel cost method, and hedonic method (Champ et al., 2003). The limitations of these methods are that they are highly vulnerable to sampling and methodology errors and so costly in time and money that it is impossible to make an estimated valuation of biodiversity on earth

\section{Comparing specialization strategy to traditional views on preserving biodiversity}

Law of comparative advantage, the basis for the specialization strategy, describes rational economic behavior. Given the law's state of nature: locales are endowed with different qualities and quantities of immobile resources; specialization in production and trade among the locales improves spatial equity in welfare caused by resource immobility. Biodiversity preservation thought is based upon a similar proposition: At different times the earth is endowed different quantities and qualities of depletable resources; human welfare over time is best achieved by using resources in such a diversified manner that resources will be least depleted.
The source of inequity in the former case is the immobility of resources; in the latter case, the depletability of resources.

The above parallel approaches are both reasonable. However, why is the specialization strategy so prevalent around the world? The answer may be that while the specialization strategy for achieving spatial equilibrium is supported by mathematical treatments (Chipman, 1965), the employment of diversified resource use strategy for optimizing welfare over time has not been rigorously treated. Then, the following question arises: why is it so difficult for the inter-temporal approaches to be structured in mathematical models? The answer lies in the nature of the approach: preservation of biodiversity requires dampening the economic instinct to employ present technologies to their fullest, even if such activity would ultimately eliminate its own resource base. The prevailing rationale is to acknowledge that the future is uncertain, to protect against that day when current technologies no longer provide a means of livelihood; one should fully exploit resources and save a portion of the gains for the future.

The temporal approach suggests restraining in the use of present resources, and leaving for the future a full range of biologically diverse factors of production. Future generations would be provided not with the saved capital of their forbearers and a reduced set of natural resources, but with a robust natural environment and restricted capital. The difference is in exchanging present capital which we know how to extract, for future capital whose means of extraction is uncertain. Here, uncertainty means we are not only aware of the impact of present technologies on environment, but also have very weak ability to predict future technologies and thus, future valuable resources (Sull and Escobari, 2004). Uncertainty of the temporal approach makes it a risk-externalizing strategy, that is, the responsibility to bear the risk of a possible decline in the effectiveness of present technologies should be external to the current economy. The contrast of this strategy with the specialization strategy is the shift in the locus of risk-taking. The riskexternalizing strategy is severely impaired by the weakness of predictive models. Faced with uncertainty about how future wealth can be insured, decision makers are likely to continue to insist upon internalized risk models, with risk compensated from current income (Costanza, 1991).

\section{COMBINING THE RISK-INTERNALIZING MODEL WITH THE DIVERSIFICATION STRATEGY}

The above discussion shows that one of the most important advantages of the specialization strategy is that, it has the internal risk-taking capacity. The intertemporal biodiversity preservation strategy is less prevalent because of its external risk-taking feature. It will 
be useful if risk internalizing model can be introduced into the biodiversity preservation strategy, denoted as the "diversification strategy" as compared to "specialization strategy". In fact, much empirical evidence is given regarding the manner in which diversity serves the enterprise of nations, firms, or even households to internalize risks. For instance, three arguments are provided

\section{Self-sufficiency argument}

Political units and some communal organizations maintain multiple enterprises in order to be as independent as possible of others. The need to support political autonomy with economic independence has led many nations to produce strategic commodities, irrespective of unfavorable domestic resource costs, and the economic advantage that would be gained by purchasing such goods abroad. The locus of risk-taking according to the self-sufficiency strategy is internal to the economy. The systems bear features that produce both stability and instability over time. It is posited to provide for stability of benefits with respect to international disruptions of commerce. Domestic enterprise is also protected from international competition, such that income streams, however inefficiently they may produce, are stable. A low level equilibrium can be achieved over time. The system, however, is exposed to disruptions in the supply of needed goods and services resulting from natural disasters or other such events internal to the economy. Multiple international sources of needed goods and services are not easily available to supplement local shortfalls.

\section{Portfolio argument}

The motivation here is to assure that within a selected set of enterprises, or securities, whatever the environmental condition, one or more income streams will strengthen and offset losses from enterprises that are unsuited to current conditions.

The portfolio strategy can be found in impoverished economies located in highly variable climatic environments. The Gunung Kidil area near Jogjakarta, Indonesia, is a case in point. In this region, each year farmers plant a combination of staple crops, maize, groundnut, pigeon pea and cassava. In any given year, one of the crops will do well, while the others fail. Heavy or light rainfall, early or late in the crop season, distinguishes the four possible outcomes, and determines which of the four crops thrives best. Since the investment in failed crops is lost, it is a high-cost system of production, limiting farmers to a low-level equilibrium income. The portfolio strategy is also found at level of cellular biology among plant breeders. Multiline pest resistance is argued to be the most effective strategy for breeding plants because when one source of resistance breaks down, another gene for resistance can take over. Breeders argue that such an approach makes it possible for a single cultivar to continue to be productive for a much longer period than a plant that has only a single line for resistance.

Advanced economies of national or household scale may follow such a strategy. Diversified portfolios of securities are advised for the risk-averse investor. Business and industrial diversification is sometimes pursued with the expectation that one product line or service area will remain prosperous when others lag. Like the Gunung Kidil farmers, the concern is for current income, with or without trade, and with no specific expectation of technical interaction among activities.

\section{Technical complementary argument}

Diversification is also undertaken to increase overall productivity and/or economic efficiency among related enterprises. During the late 1960s and early 1970s, industrial and business firms aggressively pursued the gains expected from combining related enterprises. Mergers and takeovers were said to produce synergies, or what economists term "complementarities" in production.

This strategy has also been applied to agricultural production. Mixed cropping systems or animal and crop systems are often followed in agriculture because of productivity increasing relationships among different crops grown consecutively or simultaneously in mixed patterns (Birgitta et al., 2002). Also, among different crop, animal and household enterprises there may be opportunities for products or by-products of one enterprise to be used as inputs in another (Thomas et al., 2002).

Diversification may be undertaken also to more fully utilize fixed capital such as land, buildings or family labor. Such within-firm opportunities usually affect favorable output/input relationships compared to those experienced when the separate enterprises are operated independently.

In summary, these three diversification strategies can be identified, as follows:

(1) Diversification for self-sufficiency

(2) Offsetting losses and gains

(3) Increased productivity

However, we should note that the argument for linking the state of nature - the natural diversity of biological resources - to diversification in economic activity for the purpose of cross temporal equilibrium, is not as rigorously derivable as Ricardo' argument for specialization for the purpose of cross-national (or spatial) equilibrium. 


\section{MORE APPLICATIONS OF DIVERSIFICATION STRATEGY IN AGRICULTURE IN DEVELOPING COUNTRIES}

It does make sense that the application of diversification strategy in the agriculture sector in developing countries is a mutually beneficial situation. On one hand, diversification strategy emphasizes the exploitation of multiple resources, rather than specialized in a single or few resources, leading to the long run coexistence among biological resources. On the other hand, proper diversification strategies in agriculture will support farmers' independence and increase their production. For example, mixed cropping, mixed crop and animal production, complex combinations of interactive farm enterprises, vertical integration through increased onfarm production of farm inputs and increased processing of farm outputs, are all considered to be methods of preserving biological diversity. It is reasoned that the diversification of practices in production and processing, tend to reduce farmers' needs for purchase inputs. Such practices, it is argued, reduce damage to the environment (Lin, 2011). One specific area where such an effect is said to be evident is in pest management. Plenty of the techniques named above, and others that are collectively included in "integrated pest management", have been shown to reduce pest incidence. Lin (2011) pointed out that crop diversification creates a more diverse agro ecosystem that will perform better in pest suppression and food production, when facing climate change. Another area of scientific effort is nutrient recycling, utilizing systems of composting, cover crops and other systems, which may substitute for chemical fertilizers. Other ongoing effort is to substitute water conservation methods such as no-till cultivation and soil mulches for irrigation. Yet another effort is directed to the use of animal powered equipment, to provide for beneficial interactions of livestock and cropping systems. These examples are cited because they substitute for the four key elements of modern farming technologies that have been most called into question by environmentalists: chemical pesticides, inorganic fertilizers, artificial irrigation and farm mechanization. A counter example is that landscape simplification, which transforms many landscapes into expansive monoculture with few natural habitats, results in greater pest pressure (Meehan et al., 2011)

Provided with a diversity of natural resources it was not easy for farmers to specialize according to the derived dictates of the law of comparative advantage. This is especially true for individual farmers in developing countries. Over even small spaces, natural processes had produced differences in soil fertility, water availability, vegetative cover that favored a variety of pests and diseases, and exposure to solar radiation and other factors that influence production. The superimposed variations of water, soils, pest and solar radiation regimes produced many small micro regimes, each of which, in its best use, required a different management technique different crops or other technology. Of course, diversification strategy in agriculture requires higher management capacity and increases the cost of management per unit of output. One possibility, however, is that diversification for the purpose of biodiversity preservation might be combined with one or more of the strategies for diversification: self-sufficiency, off-setting gains and losses, or production complementarities. Combining the welfare of preserving biological diversity with the benefits obtained from complementarities in production may offer a way of offsetting the higher managerial costs of biologically diverse production systems. Complementarities among enterprises might even be sufficient to more than pay for higher management costs, and thus provide for some additional net increase in productivity. Ruttan (1989) suggested that the latter is necessary in order for sustainable agricultural systems to meet our needs as population and incomes increase. In addition, the accessibility of local processing facilities is a key factor that limits diversified agriculture.

\section{DISCUSSION}

The specialization strategy emphasizes welfare among nations, or spatial equity. Biodiversity preservation addresses the inter-temporal distribution of welfare. The locus of risk-taking is internal to the first strategy, and external to the latter. This review introduces a diversification strategy, which tries to combine the environmental objective with the internalized risk models. By internalizing risks, the diversification strategy is found to not only conserve natural resources, but also (a) selfsufficiency, (b) offsetting losses and gains, and (c) technical complementary. It is also argued that diversification strategies may play an active role in biodiversity preservation for developing countries, especially the fragile conflict-prone countries. A potential approach for developing countries to keep balance between biodiversity preservation and increasing productivity is to apply a risk-internalized diversification model that suits local circumstances.

A discussion of agricultural research is included as an extension of this article. The belief in specialization is especially strong among agricultural research organizations. Specialization induces a philosophy of management that suggests always investing most research resources where there has been greatest success in the past. The international research centers are a good example. Many have a commodity focus, and there is general belief that to stray from research on their mandated commodities will lead to unproductive research investment. The restriction goes even further to suggest that research on the commodity should focus on those aspects in which there has been greatest success, for 
example, lowland irrigated rice. The guiding principle is to continue to do what is believed to be done best. However, diversification strategy can be argued to deserve equal attention. Firstly, focusing on one commodity in research incurs the risk of total failure in case that the single commodity enterprise fails. Besides reducing the research organization's risk by spreading research across select commodities, diversification can increase benefits, utilizing and leveraging core facilities or administration across commodities enterprises. In fact, it is possible that the research organization's core commodity research would be benefited from studying other commodities, or cooperating with other institutions.

\section{REFERENCES}

Birgitta R, Lennartsson M, Davies G (2002). The use of mixed species cropping to manage pests and diseases - theory and practice. Presented at the UK Organic Research 2002 Conference in University of Wales Aberystwyth. pp. 207-210.

Bishop R (1993). Economic efficiency, sustainability, and biodiversity. A J. Hum. Environ. 22(2-3):69-73.

Champ P, Boyle K, Brown T (2003). A primer on nonmarket valuation. Kluwer Academic Publishers, Dordrecht, the Netherlands.

Chipman J (1965). A Survey of the theory of international trade: Part I, Classical Theory. Econometrica 33(3):477-519.

Chisholm M (1962). Tendencies in agricultural specialization and regional concentration of industry. Regional Sci. 10(1):157-162

Costanza R (1991). Ecological Economics: The Science and Management of Sustainability. New York, Columbia University Press.

Davis D, Weinstein D (1999). Economic geography and regional production structure: and empirical investigation. Eur. Econ. Rev. 43(2):379-407.

Day G (1981). The product life cycle: analysis and applications issues. J. Market. 45(4):60-67

Deming E (1994). The new economics for industry, government, education. The MIT Press, Cambridge, Massachusetts.

Fisher A, Krutilla J, Cicchetti C (1972). The economics of environmental preservation: a theoretical and empirical analysis. Am. Econ. Rev. 62(4):605-619.

Gowdy J, McDaniel C (1995). One world, one experiment: addressing the biodiversity- economics conflict. Ecol. Econ. 15:181-192

Gowdy J (1997). The Value of biodiversity: markets, society, and ecosystems. Land Economics, 73(1):25-41.
Gregson M (1996). Long-term trends in agricultural specialization in the United States: some preliminary results. Agric. History 70(1):90-101.

Hilborn R, Walters C, Ludwig D (1995). Sustainable exploitation of renewable resources. Ann. Rev. Ecol. Systemat. 26:45-67.

Jones R (1961). Comparative advantage and the theory tariffs: a multicountry, multi- commodity model. Rev. Econ. Stud. 77:161-175.

Lin B (2011). Resilience in agriculture through crop diversification: adaptive management for environmental change. BioScience 62(3):183-193

Lyons T (1988). Concentration and specialization in Chinese agriculture, 1979-1985. J. Dev. Areas 22(4):437-456.

McNeely J (2003). Conserving forest biodiversity in times of violent conflict. Int. J. Conserv. 37(2):142-152.

Meehan T, Werling B, Landis D, Gratton C (2011). Agricultural landscape simplification and insecticide use in the Midwestern United States. Proceedings of the national academy of sciences of the U.S.A. 108(28):11500-11505.

Norton B (1988). Commodity, amenity, and morality: the limits of quantification in valuing biodiversity. National Academy Press, Washington, DC.

Randall A (1991). The value of biodiversity. A.J. Hum.Environ.20(2):6468.

Regev U, Gutierrez A, Schreiber S, Zilberman D (1998). Biological and economic foundations of renewable resource exploitation. Ecol. Econ. 26:227-242.

Ruttan V (1989). Sustainability is not enough. Am. J. Altern. Agric. 3(23):128-130.

Ricardo D (1817). On the principles of political economy and taxation. London.

Shiozawa $Y$ (2007). A new construction of ricardian trade theory-A many-country, many- commodity case with intermediate goods and choice of production techniques. Evolution. Institut. Econ. Rev. $3(2): 141-187$

Solow R (1993). Sustainability: an economist's perspective. Norton Press, New York.

Sull D, Escobari M (2004). Creating value in an unpredictable world. Bus. Strat. Rev. 15(3):14-20.

Thomas D, Zerbini E, Rao P, Vaidyanathan A (2002). Increasing animal productivity on small mixed farms in South Asia: a systems perspective. Agric. Sys. 71(1):41-57.

Tietenberg T (2009). Environmental Economics and Policy. Addison Wesley, Boston.

Torrens R (1815). An Essay on the External Corn Trade. London.

Unruh J, Gibson D, Woods K (2008). Biodiversity conservation and crisis. USAID. 